\title{
Neoadjuvant Chemotherapy Versus Chemoradiotherapy for Patients with Esophageal Squamous Cell Carcinoma
}

\author{
YUICHIRO NAKASHIMA ${ }^{1}$, HIROSHI SAEKI ${ }^{1}$, QINGJIANG HU ${ }^{1}$, YASUO TSUDA ${ }^{1}$, \\ YUICHI HISAMATSU ${ }^{1}$, KOJI ANDO ${ }^{1}$, EIJI OKI ${ }^{1}$ and YOSHIHIKO MAEHARA ${ }^{2}$ \\ ${ }^{1}$ Department of Surgery and Science, Graduate School of Medical Sciences, Kyushu University, Fukuoka, Japan; \\ ${ }^{2}$ Department of Surgery, Kyushu Central Hospital of the Mutual \\ Aid Association of Public School Teachers, Fukuoka, Japan
}

\begin{abstract}
Aim: To confirm the superiority of neoadjuvant chemoradiotherapy (NACRT) over neoadjuvant chemotherapy (NAC) as preoperative therapy for locally advanced esophageal cancer. Patients and Methods: A total of 298 patients with resectable esophageal cancer were initially enrolled; 62 patients received NAC and 236 patients received NACRT. Propensity score matching was applied to create a study cohort. Results: Postoperative 30-day mortality rate, overall postoperative complication rate, and overall survival time did not differ between those groups. Complete pathological response occurred in one patient treated with $N A C$ and 16 treated with NACRT $(p<0.001)$. In patients with borderline-resectable $T 4$ disease, overall survival was superior in the NACRT group compared to that in the NAC group $(p=0.040)$. Conclusion: No survival advantage was observed between NAC and NACRT groups. Limited to patients with borderline-resectable T4, NACRT achieved a higher rate of primary tumor volume reduction and $R O$ resection, and a more favorable prognosis compared to NAC.
\end{abstract}

Since most patients with esophageal cancer are diagnosed at a locally advanced stage and therefore have a poor prognosis, it remains one of the most difficult digestive tract malignancies to control by surgery alone (1). In order to improve the longterm survival of patients who undergo surgery, neoadjuvant therapy has emerged as a potential treatment. Neoadjuvant therapy methods include neoadjuvant chemotherapy (NAC) and neoadjuvant chemoradiotherapy (NACRT). The clinical

Correspondence to: Yoshihiko Maehara, MD, Ph.D., FACS, Department of Surgery, Kyushu Central Hospital of the Mutual Aid Association of Public School Teachers, 3-23-1 Shiohara, Minamiku, 815-8588, Fukuoka, Japan. Tel: +81 925414936, Fax: +81 925414540,e-mail: maehara@surg2.med.kyushu-u.ac.jp

Key Words: Esophageal squamous cell carcinoma, neoadjuvant chemotherapy, neoadjuvant chemoradiotherapy. results of some prospective and retrospective studies, as well as meta-analyses, have emphasized the superiority of NACRT plus surgery over NAC plus surgery, although the majority of studies did not demonstrate a significant difference (2-9). However, all of these studies and meta-analyses were conducted in Western countries, and almost all enrolled patients had adenocarcinoma histology; very few patients with squamous cell carcinoma were included. In contrast, squamous cell carcinoma is the dominant pathological type of esophageal cancer in East Asia, including Japan (1). No recent studies have specifically compared NAC to NACRT for locally advanced esophageal squamous cell carcinoma.

The aim of the present study was to compare the clinical benefits of NAC versus NACRT for esophageal cancer patients in our Institute, located in Japan. We conducted a retrospective analysis of the surgical and pathological results and prognosis of patients with advanced esophageal cancer who underwent two types of neoadjuvant therapy followed by esophagectomy using a propensity score-matching analysis to evaluate the outcomes without selection bias.

\section{Patients and Methods}

Study participants. A total of 806 patients underwent esophagectomy for esophageal cancer between January 1991 and December 2015 at the Department of Surgery and Science (Department of Surgery II) of Kyushu University Hospital in Japan. This study included 298 patients with resectable clinical stage II, III, or IV disease, excluding patients with clinical T4 (unresectable) or distant metastasis, who received neoadjuvant therapy. Patients were retrospectively categorized into two groups based on neoadjuvant therapy: NAC with chemotherapy only (62 cases) and NACRT with a total radiotherapy dose of 30-45 Gy combined with chemotherapy (236 cases). Clinicopathological factors were classified according to the system used by the Japan Esophageal Society $(10,11)$. 'Borderline-resectable T4' was further classified as locally advanced esophageal cancer suspected of invading adjacent organs, but not definitively diagnosed as T4 disease, as previously described (12). Esophagectomy was classified as either curative (R0) or noncurative (R1, R2) surgery $(10,11,13)$. 
Treatment strategies. Esophagectomy was performed 4-6 weeks after the termination of NAC or NACRT. In the NAC group, the chemotherapy regimen most commonly consisted of either standarddose cisplatin and 5-fluorouracil (5-FU) $\left(80 \mathrm{mg} / \mathrm{m}^{2} /\right.$ day cisplatin on days 1 and 29;800 mg/m²/day 5-FU on days $1-4$ and 29-32) or docetaxel, cisplatin, and 5 -FU $\left(40 \mathrm{mg} / \mathrm{m}^{2} /\right.$ day docetaxel on days 1 , 15,29 , and $43 ; 80 \mathrm{mg} / \mathrm{m}^{2} /$ day cisplatin on days 1 and $29 ; 800$ $\mathrm{mg} / \mathrm{m}^{2} /$ day $5-\mathrm{FU}$ on days $1-4$ and $29-32$ ). In the NACRT group, the chemotherapy regimen most commonly consisted of either standarddose cisplatin and 5-FU (70 mg/m²/day cisplatin on days 1 and 29; $700 \mathrm{mg} / \mathrm{m}^{2} /$ day 5 -FU on days $1-4$ and $29-2$ ) or a low-dose cisplatin $/ 5$-FU regimen $\left(5 \mathrm{mg} / \mathrm{m}^{2} /\right.$ day cisplatin; $250 \mathrm{mg} / \mathrm{m}^{2} /$ day 5 FU; treatment was administered on weekdays and repeated every 3 4 weeks). Radiotherapy was delivered using equally weighted anterior- and posterior-opposed beams from a 10-MV linear accelerator in 15-25 fractions of 1.8-2.0 Gy (total dose=30-45 Gy).

As a standard approach for thoracic esophageal cancer, either subtotal esophagectomy and cervical anastomosis, or distal esophagectomy and intrathoracic anastomosis have been adopted at our hospital. For patients with upper- or mid-thoracic esophageal cancer or with lower-thoracic esophageal cancer, subtotal esophagectomy is generally performed. Distal esophagectomy was usually indicated either for patients with early-stage cancer located primarily in the lowerthoracic and sometimes mid-thoracic esophagus. For patients with cervical esophageal cancer, cervical esophagectomy with laryngectomy was the standard procedure, while a blunt dissection of the esophagus with laryngectomy was occasionally performed.

Postoperative complications. Postoperative complications that developed within 30 days after esophagectomy and required medication or surgical intervention were evaluated according to Clavien-Dindo classification. Pulmonary complications included pneumonia (defined as a positive bacterial sputum culture), atelectasis, or hypoxia requiring reintubation. Anastomotic leakage was diagnosed using esophagography or fistelography, as well as by discharge of saliva through the fistula.

Pathological efficacy of NAC and NACRT. Based on the criteria outlined in Guidelines for the Clinical and Pathologic Studies on Carcinoma of the Esophagus by the Japan Esophageal Society, the effects of neoadjuvant therapy were classified as grade 3, marked response; grade 2, moderate response; grade 1, slightly effective; and grade 0 , ineffective results $(10,11)$.

Statistical analysis. Differences in distribution frequencies between groups were evaluated using Fisher's exact test or unpaired $t$-test. Survival curves were plotted according to the Kaplan-Meier method, and differences were analyzed using the log-rank test. A propensity score was calculated using logistic regression analysis based on the following variables: sex, age, tumor location, depth of tumor invasion, degree of lymph node involvement, histological tumor type, and type of esophagectomy. Differences were considered to be significant when the $p$-value was less than 0.05 . Data were analyzed using JMP11 software (SAS Institute Inc., Cary, NC, USA).

\section{Results}

Patients and tumor demographics. Before matching, patients in the NAC group had more cT1 tumors (6/62 cases; $9.7 \%)$ and fewer cT3 tumors (42/62 cases; 67.7\%) compared to
Table I. Demographic and therapeutic characteristics of patients who received neoadjuvant chemotherapy (NAC) or neoadjuvant chemoradiotherapy (NACRT) according to propensity score matching.

\begin{tabular}{|c|c|c|c|}
\hline Factor & $\begin{array}{c}\text { NAC group } \\
n=60\end{array}$ & $\begin{array}{c}\text { NACRT group } \\
n=60\end{array}$ & $p$-Value \\
\hline \multicolumn{4}{|l|}{ Gender, n (\%) } \\
\hline Male & $49(81.7)$ & $54(90.0)$ & \multirow[t]{2}{*}{0.2950} \\
\hline Female & $11(18.3)$ & $6(10.0)$ & \\
\hline \multicolumn{4}{|l|}{ Age at surgery, years } \\
\hline Median & 64.2 & 63.6 & 0.6762 \\
\hline \multicolumn{4}{|l|}{ Location, n (\%) } \\
\hline Upper & $4(6.7)$ & $3(5.0)$ & \multirow[t]{3}{*}{0.7170} \\
\hline Middle & $55(91.7)$ & $57(95.0)$ & \\
\hline Lower & $1(1.7)$ & $0(0.0)$ & \\
\hline \multicolumn{4}{|l|}{ Clinical tumor depth, n (\%) } \\
\hline $\mathrm{cT} 1 \mathrm{~b}$ & $4(6.7)$ & $4(6.7)$ & \multirow[t]{3}{*}{0.6174} \\
\hline cT2 & $14(23.3)$ & $11(18.3)$ & \\
\hline cT3 & $42(70.0)$ & $45(75.0)$ & \\
\hline \multicolumn{4}{|l|}{ Clinical nodal status, n (\%) } \\
\hline cNo & $17(27.9)$ & $14(23.3)$ & \multirow[t]{5}{*}{0.9500} \\
\hline $\mathrm{cN} 1$ & $12(20.0)$ & $12(20.0)$ & \\
\hline $\mathrm{cN} 2$ & $19(31.7)$ & $22(36.7)$ & \\
\hline $\mathrm{cN} 3$ & $11(18.3)$ & $11(18.3)$ & \\
\hline $\mathrm{cN} 4$ & $1(1.7)$ & $1(1.7)$ & \\
\hline \multicolumn{4}{|l|}{ Clinical stage, n (\%) } \\
\hline cStage II & $20(33.3)$ & $20(33.3)$ & \multirow[t]{3}{*}{$>0.9999$} \\
\hline cStage III & $39(65.0)$ & $39(65.0)$ & \\
\hline cStage IV & $1(1.7)$ & $1(1.7)$ & \\
\hline \multicolumn{4}{|l|}{ Histology, n (\%) } \\
\hline Squamous cell carcinoma & $59(98.3)$ & $59(98.3)$ & \multirow[t]{2}{*}{$>0.9999$} \\
\hline Adenocarcinoma & $1(1.7)$ & $1(1.7)$ & \\
\hline \multicolumn{4}{|l|}{ Type of esophagectomy, n (\%) } \\
\hline Subtotal & $59(98.3)$ & $59(98.3)$ & \multirow[t]{2}{*}{$>0.9999$} \\
\hline Lower & $1(1.7)$ & $1(1.7)$ & \\
\hline
\end{tabular}

patients in the NACRT group, with $1.7 \%(4 / 236)$ and $80.5 \%$ (190/236 cases), respectively $(p=0.0072)$. Other baseline characteristics and types of surgery did not differ significantly between groups. Table I summarizes the clinicopathological characteristics and type of esophagectomy in matched patients. After matching, no significant differences were observed between groups for all characteristics and surgeries. Almost all cases had squamous cell carcinoma (118/120 patients; 98.3\%); only $2 / 120$ patients (1.7\%) had adenocarcinoma.

The chemotherapy regimens used in both groups are summarized in Table II. For NAC, standard cisplatin and 5FU were most frequently given $(26 / 60 ; 43.3 \%)$, followed by docetaxel, cisplatin, and 5-FU (13/60; 21.7\%). For NACRT, low-dose cisplatin and 5-FU were most frequently used $(30 / 60 ; 50.0 \%)$, followed by the standard cisplatin and $5-\mathrm{FU}$ regimen $(14 / 60 ; 23.3 \%)$. Significantly fewer courses of the standard cisplatin and 5-FU regimen were given in the NACRT group (1.6 courses) than in the NAC group (1.9 courses; $p=0.041$ ). 
Table II. Chemotherapy regimens used in this study.

\begin{tabular}{|c|c|c|c|c|c|}
\hline \multirow[b]{2}{*}{ Chemotherapy agent } & \multicolumn{2}{|c|}{ NAC } & \multicolumn{2}{|c|}{ NACRT } & \multirow[b]{2}{*}{$p$-Value } \\
\hline & $\mathrm{n}(\%)$ & No. of courses & $\mathrm{n}(\%)$ & No. of courses & \\
\hline Cisplatin/5-FU* & $26(43.3)$ & $1.9 \pm 0.3$ & $14(23.3)$ & $1.6 \pm 0.9$ & 0.0411 \\
\hline Low-dose cisplatin/5-FU ${ }^{\dagger}$ & $1(1.7)$ & $2.0 \pm 0.0$ & $30(50.0)$ & $2.6 \pm 1.0$ & 0.4860 \\
\hline Cisplatin/docetaxel/5-FU & $13(21.7)$ & $1.9 \pm 0.8$ & $0(0.0)$ & - & $>0.9999$ \\
\hline Cisplatin/bleomycin & $11(18.3)$ & $3.0 \pm 0.0$ & $0(0.0)$ & - & $>0.9999$ \\
\hline Cisplatin/docetaxel & $1(1.7)$ & $1.0 \pm 0.0$ & $0(0.0)$ & - & $>0.9999$ \\
\hline Cisplatin only & $3(5.0)$ & $3.0 \pm 0.0$ & $14(23.3)$ & $2.9 \pm 0.3$ & 0.6434 \\
\hline Other & $5(8.3)$ & - & $2(3.3)$ & - & $>0.9999$ \\
\hline
\end{tabular}

$* 80 \mathrm{mg} / \mathrm{m}^{2}$ cisplatin and $800 \mathrm{mg} / \mathrm{m}^{2}$ 5-fluorouracil (5-FU) were given to patients treated with neoadjuvant chemotherapy (NAC); $70 \mathrm{mg} / \mathrm{m}^{2} \mathrm{cisplatin}$ and $700 \mathrm{mg} / \mathrm{m}^{2} 5$-FU were given to patients treated with neoadjuvant chemoradiotherapy (NACRT). $\dagger 10 \mathrm{mg} / \mathrm{m}^{2} \mathrm{cisplatin}$ and $500 \mathrm{mg} / \mathrm{m}^{2} 5-\mathrm{FU}$ were given to both groups.

Table III. Postoperative complications experienced by patients who received neoadjuvant chemotherapy (NAC) or neoadjuvant chemoradiotherapy (NACRT).

\begin{tabular}{lccc}
\hline Factor & $\begin{array}{c}\text { NAC } \\
\text { group } \\
\mathrm{n}=60\end{array}$ & $\begin{array}{c}\text { NACRT } \\
\text { group } \\
\mathrm{n}=60\end{array}$ & $p$-Value \\
& & & \\
\hline $\begin{array}{l}\text { Anastomotic leak, n (\%) } \\
\quad \text { No }\end{array}$ & $38(64.4)$ & $46(76.7)$ & 0.1627 \\
$\quad$ Yes & $21(35.6)$ & $14(23.3)$ & \\
Pulmonary complications, n (\%) & & & \\
$\quad$ No & $56(93.3)$ & $54(90.0)$ & 0.7430 \\
$\quad$ Yes & $4(6.7)$ & $10(10.0)$ & \\
$\begin{array}{l}\text { Overall complications, n (\%) } \\
\quad \text { No }\end{array}$ & $33(55.0)$ & $35(58.3)$ & 0.8540 \\
$\quad$ Yes & $27(45.0)$ & $25(41.7)$ & \\
$\begin{array}{l}\text { 30-Day mortality, n (\%) } \\
\quad \text { No }\end{array}$ & $60(100)$ & $58(96.7)$ & 0.4958 \\
$\quad$ Yes & $0(0.0)$ & $2(3.3)$ & \\
In-hospital mortality, n (\%) & & & \\
$\quad$ No & $59(98.3)$ & $57(95.0)$ & 0.6186 \\
$\quad$ Yes & $1(1.7)$ & $3(5.0)$ & \\
\hline
\end{tabular}

Postoperative complications and tumor response. Table III lists the postoperative complications and hospital mortality in both groups. Neither postoperative complications (anastomotic leak and pulmonary and overall complications) nor perioperative mortality (30-day mortality and in-hospital death) significantly differed between groups.

A greater number of patients treated with NACRT experienced a pathological complete response (grade 3) compared to those treated with NAC $(16 / 60 ; 26.7 \%$ versus $1 / 60 ; 1.7 \% ; p<0.0001)$. Pathological down-staging with respect to tumor depth was significantly more frequent in
Table IV. Histopathology and post-operative staging of patients who received neoadjuvant chemotherapy (NAC) or neoadjuvant chemoradiotherapy (NACRT).

\begin{tabular}{|c|c|c|c|}
\hline Factor & $\begin{array}{l}\text { NAC } \\
\text { group } \\
n=60\end{array}$ & $\begin{array}{c}\text { NACRT } \\
\text { group } \\
n=60\end{array}$ & $p$-Value \\
\hline \multicolumn{4}{|c|}{ Margin status, $\mathrm{n}(\%)$} \\
\hline R0 & $49(81.7)$ & $45(75.0)$ & \multirow[t]{2}{*}{0.5068} \\
\hline $\mathrm{R} 1,2$ & $11(18.3)$ & $15(25.0)$ & \\
\hline \multicolumn{4}{|c|}{ Histological response, n (\%) } \\
\hline Grade 0,1 & $51(85.0)$ & $22(36.7)$ & \multirow[t]{3}{*}{$<0.0001$} \\
\hline Grade 2 & $8(13.3)$ & $22(36.7)$ & \\
\hline Grade 3 & $1(1.7)$ & $16(26.7)$ & \\
\hline \multicolumn{4}{|c|}{ Pathological tumor depth, n (\%) } \\
\hline pT0 & $1(1.7)$ & $16(26.7)$ & \multirow[t]{5}{*}{0.0032} \\
\hline pT1 & $7(11.7)$ & $5(8.3)$ & \\
\hline pT2 & $13(21.7)$ & $11(18.3)$ & \\
\hline pT3 & $33(55.0)$ & $25(41.7)$ & \\
\hline pT4 & $6(10.0)$ & $3(5.0)$ & \\
\hline \multicolumn{4}{|c|}{ Pathological nodal status, n (\%) } \\
\hline pNo & $22(36.7)$ & $28(46.7)$ & \multirow[t]{5}{*}{0.6965} \\
\hline $\mathrm{pN} 1$ & $8(13.3)$ & $5(8.3)$ & \\
\hline $\mathrm{pN} 2$ & $16(26.7)$ & $14(23.3)$ & \\
\hline $\mathrm{pN} 3$ & $10(16.7)$ & $11(18.3)$ & \\
\hline $\mathrm{pN} 4$ & $4(6.7)$ & $2(3.3)$ & \\
\hline \multicolumn{4}{|c|}{ Pathological stage, n (\%) } \\
\hline 0 & $2(3.3)$ & $11(18.3)$ & \multirow[t]{5}{*}{0.0148} \\
\hline I & $3(5.0)$ & $5(8.3)$ & \\
\hline II & $19(31.7)$ & $16(26.7)$ & \\
\hline III & $29(48.3)$ & $25(41.7)$ & \\
\hline IV & $7(11.7)$ & $3(5.0)$ & \\
\hline
\end{tabular}

patients treated with NACRT compared to those treated with NAC (Table IV). For completeness of resection (R0) and pathological down-staging based on nodal status, no significant differences were observed between groups. 

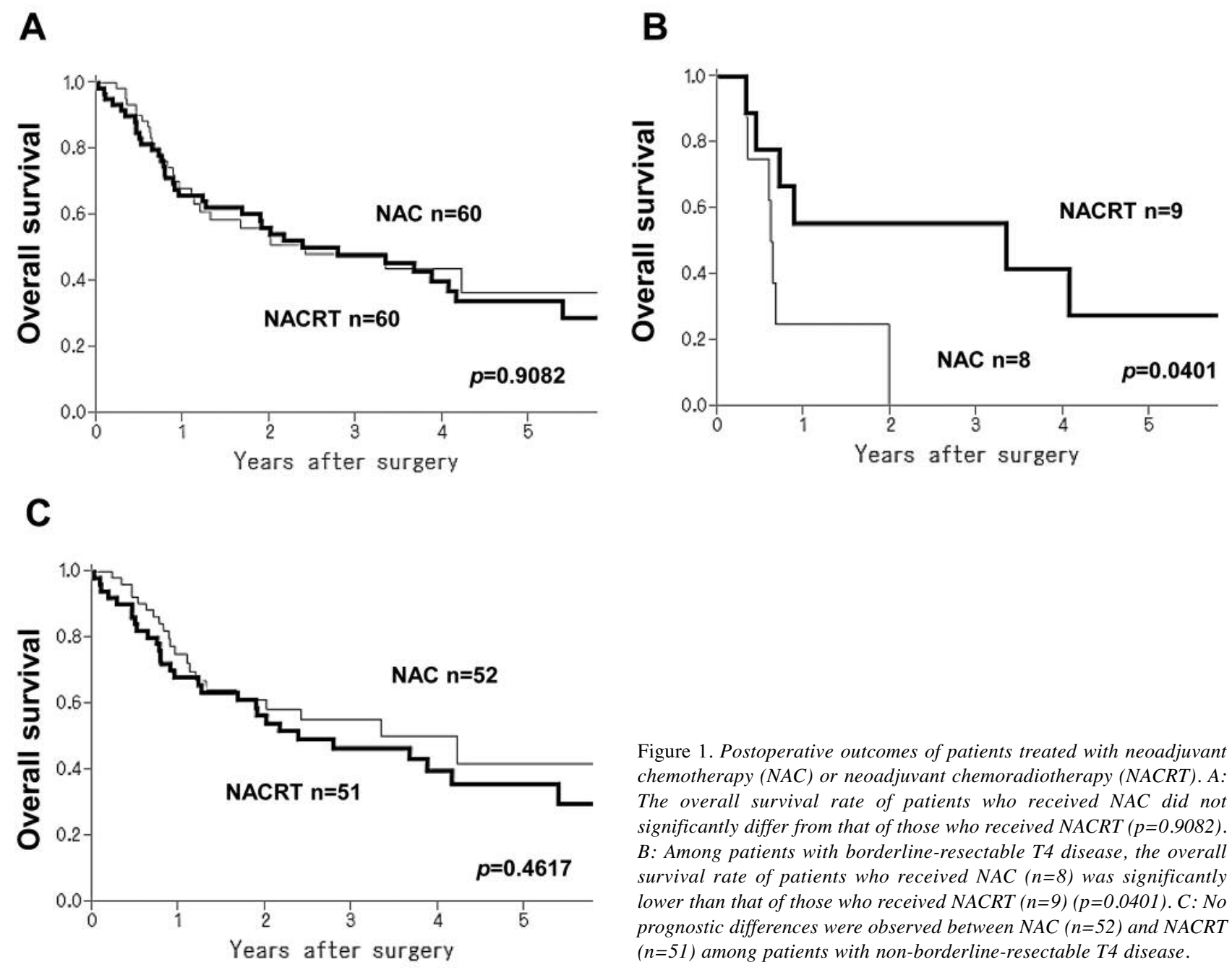

Figure 1. Postoperative outcomes of patients treated with neoadjuvant chemotherapy (NAC) or neoadjuvant chemoradiotherapy (NACRT). A: The overall survival rate of patients who received NAC did not significantly differ from that of those who received NACRT ( $p=0.9082)$. $B$ : Among patients with borderline-resectable T4 disease, the overall survival rate of patients who received NAC $(n=8)$ was significantly lower than that of those who received NACRT $(n=9)(p=0.0401)$. C: No prognostic differences were observed between NAC $(n=52)$ and NACRT $(n=51)$ among patients with non-borderline-resectable T4 disease.

Long-term prognosis. Figure 1 shows the postoperative outcomes of patients who received NAC or NACRT. The 5year overall survival rate and median survival time of the patients who received NAC $(36.6 \%$ and 2.41 years, respectively) did not significantly differ from those of patients treated with NACRT (33.9\% and 2.79 years, respectively; log-rank, $p=0.9082$; Figure 1A). The postoperative outcomes of patients who received NAC or NACRT based on whether or not they had borderlineresectable T4 disease are shown in Figure $1 \mathrm{~B}$ and $\mathrm{C}$. The 5 -year overall survival rate $(0.0 \%$ vs. $27.8 \%)$ and median survival time (0.62 versus 3.34 years) of patients with borderline-resectable T4 disease who received NAC $(n=8)$ were significantly poorer than those of patients who received NACRT ( $n=9$; log-rank, $p=0.0401$ ), whereas no differences were observed among those with non-borderline-resectable T4 disease $(n=103)$.

\section{Discussion}

The randomized phase III trial JCOG9907 for patients with clinical stage II and III esophageal cancer confirmed a survival benefit associated with NAC using cisplatin plus 5-FU regimen over adjuvant chemotherapy with the same regimen (14). NAC has, therefore, become the current standard treatment in Japan for locally advanced esophageal cancer. In a subgroup analysis of JCOG9907, no significant difference in overall survival was observed between NAC and adjuvant chemotherapy among patients with clinical stage III disease (14). At our Institute, NAC has also been introduced as a standard neoadjuvant treatment for locally advanced esophageal cancer. However, NACRT has also been introduced to patients with disease suspected of invading adjacent organs but not definitively diagnosed as T4 disease. 
One meta-analysis (3) and one review (9) addressing the superiority of NACRT and NAC in esophageal cancer have been published; both reports reviewed five studies in common, consisting of two randomized controlled trials $(2,7)$, two prospective series $(5,8)$, and one retrospective study (4). All five reported that patients who received NACRT tended to experience higher postoperative complication rates compared to those who received NAC; however, the difference was not statistically significant $(2,4,5,7,8)$. Furthermore, all these studies reported a significantly higher postoperative pathological complete response rate for NACRT versus NAC $(2,4,5,7,8)$. In addition, NACRT tended to be associated with longer survival compared to NAC $(2,4,5,7)$; however, only one study demonstrated a statistically significant survival difference (8). Almost all enrolled patients had disease with adenocarcinoma histology; patients with squamous cell carcinoma were rare $(2,4,5,7,8)$.

Based on these studies in esophageal adenocarcinoma (25, 7-9), we hypothesized that adding radiation therapy to NAC may provide a higher rate of down-staging and a marked histopathological response among patients with locally advanced esophageal squamous cell carcinoma. Since a marked histopathological response to chemoradiotherapy very likely indicates a better prognosis following esophagectomy among patients with locally advanced esophageal squamous cell carcinoma $(13,15)$, we anticipated the addition of radiation therapy would result in an improvement in long-term survival.

The principal finding of this study was that patients who received NACRT experienced a marked histopathological response without an elevated risk of surgical complications compared to those who received NAC; however, no difference in long-term prognosis was observed between the groups. In addition, a subgroup analysis demonstrated that the addition of radiation therapy to NAC provided longer survival among patients with borderline-resectable T4 disease. Three prospective trials $(2,5,7)$, and one retrospective study (4) of esophageal adenocarcinoma reported similar results with respect to surgical complications, histopathological complete response, and long-term prognosis. Although the rate of marked histopathological response in patients was increased from $1.7 \%$ with NAC to $26.7 \%$ with NACRT, the overall survival rate did not differ between the two neoadjuvant treatment groups. This complete pathological response rate was consistent with that for esophageal adenocarcinoma, which has been reported to be only $2-8 \%$ with NAC compared to $16-31 \%$ with NACRT $(2,4,5,7,8)$. One hypothesis to explain this may be that the addition of localized treatment, such as radiation therapy, to appropriate surgery in patients who undergo NACRT may not influence survival potential since this disease has a high rate of occult systemic metastasis. In the present series, both the doses and number of administered courses of neoadjuvant cisplatin plus 5-FU regimen were significantly lower in the NACRT group, than in the NAC group. The dose intensity of the NACRT regimen, which was set by considering the toxicity associated with radiation therapy, may have been insufficient as systemic chemotherapy for preventing distant metastasis after surgery.

The major limitation of the present study is its design: it was performed at a single institution and was retrospective. Therefore, the estimated effects of prognostic variables were adjusted for the propensity score using Cox proportional hazards model. The second limitation is that interpretation of the results of this study must differ from that for an intentto-treat analysis of a prospective study. For example, information from patients who experienced tumor progression due to a lack of response to neoadjuvant treatment and whose disease therefore became unresectable was not considered because only patients who underwent esophagectomy were enrolled. Another limitation of this study is that the neoadjuvant chemotherapy agents differed between groups (Table II). This difference may have led to the discrepancies in histopathological response and prognosis between the two neoadjuvant treatment groups.

In conclusion, our data failed to confirm the superiority of NACRT over NAC as neoadjuvant treatment in patients with resectable esophageal cancer. However, particularly for borderline-resectable T4 cases, NACRT may improve postoperative survival with an increased response rate, which will enable more patients to undergo curative surgery. To date, no randomized controlled trials have compared NAC and NACRT in patients with esophageal squamous cell carcinoma (16). Based on the results of JCOG9907, the three-arm phase III JCOG1109 trial was initiated in Japan to confirm the superiority of NACRT over NAC, both with the cisplatin plus 5-FU regimen, and the superiority of cisplatin with 5-FU and docetaxel over cisplatin plus 5-FU, as neoadjuvant therapy for esophageal squamous cell carcinoma (17). The results of this ongoing Japanese trial may reveal the optimal neoadjuvant treatment for patients with advanced resectable esophageal squamous cell carcinoma, particularly those with borderline-resectable $\mathrm{T} 4$ disease.

\section{References}

1 Morita M, Yoshida R, Ikeda K, Egashia A, Oki E, Sadanaga N, Kakeji Y, Yamanaka T and Maehara Y: Advances in esophageal cancer surgery in Japan: An analysis of 1000 consecutive patients treated at a single institute. Surgery 143: 499-508, 2008.

2 Burmeister BH, Thomas JM, Burmeister EA, Walpole ET, Harvey JA, Thomson DB, Barbour AP, Gotley DC and Smithers $\mathrm{BM}$ : Is concurrent radiation therapy required in patients receiving preoperative chemotherapy for adenocarcinoma of the oesophagus? A randomised phase II trial. Eur. J Cancer 47: 354$360,2011$. 
3 Fan M, Lin Y, Pan J, Yan W, Dai L, Shen L and Chen K: Survival after neoadjuvant chemotherapy versus neoadjuvant chemoradiotherapy for resectable esophageal carcinoma: A metaanalysis. Thorac Cancer 7: 173-181, 2016.

4 Luu TD, Gaur P, Force SD, Staley CA, Mansour KA, Miller JI Jr, Miller DL: Neoadjuvant chemoradiation versus chemotherapy for patients undergoing esophagectomy for esophageal cancer. Ann Thorac Surg 85: 1217-1224, 2008.

5 Morgan MA, Lewis WG, Crosby TDL, Escofet X, Roberts SA, Brewster AE, Harvard TJ and Clark GW: Prospective cohort comparison of neoadjuvant chemoradiotherapy versus chemotherapy in patients with oesophageal cancer. Br J Surg 94: 15091514, 2007.

6 Nygaard K, Hagen S, Hansen HS, Hatlevoll R, Hultborn R, Jakobsen A, Mäntyla M, Modig H, Munck-Wikland E, Rosengren B, Pre-operative radiotherapy prolongs survival in operable esophageal carcinoma: a randomized, multicenter study of pre-operative radiotherapy and chemotherapy. The second Scandinavian trial in esophageal cancer. World J Surg 16: 11041109, 1992.

7 Stahl M, Walz MK, Stuschke M, Lehmann N, Meyer HJ, RieraKnorrenschild J, Langer P, Engenhart-Cabillic R, Bitzer M, Königsrainer A, Budach W and Wilke H: Phase III comparison of preoperative chemotherapy compared with chemoradiotherapy in patients with locally advanced adenocarcinoma of the esophagogastric junction. J Clin Oncol 27: 851-856, 2009.

8 Swisher SG, Hofstetter W, Komaki R, Correa AM, Erasmus J, Lee JH, Liao Z, Maru D, Mehran R, Patel S, Rice DC, Roth JA, Vaporciyan AA, Walsh GL and Ajani JA: Improved Long-Term Outcome With Chemoradiotherapy Strategies in Esophageal Cancer. Ann Thorac Surg 90: 892-899, 2010.

9 Hamilton E, Vohra RS and Griffiths EA: What is the best neoadjuvant regimen prior to oesophagectomy: Chemotherapy or chemoradiotherapy? Int J Surg 12: 196-199, 2014

10 Japan Esophageal Society. Japanese Classifi cation of Esophageal Cancer, tenth edition: part I: Esophagus 6: 1-25, 2009.

11 Japan Esophageal Society. Japanese Classification of Esophageal Cancer, Tenth Edition: Parts II and III: Esophagus 6: 71-94, 2009.
12 Yokota $\mathrm{T}$, Hatooka S, Ura T, Abe T, Takahari D, Shitara K, Nomura M, Kondo C, Mizota A, Yatabe Y, Shinoda M and Muro $\mathrm{K}$ : Docetaxel plus 5-fluorouracil and cisplatin (DCF) induction chemotherapy for locally advanced borderline-resectable T4 esophageal cancer. Anticancer Res 31: 3535-3541, 2011.

13 Saeki H, Morita M, Tsuda Y, Hidaka G, Kasagi Y, Kawano H, Otsu H, Ando K, Kimura Y, Oki E, Kusumoto T and Maehara Y: Multimodal treatment strategy for clinical T3 thoracic esophageal cancer. Ann Surg Oncol 20: 4267-4273, 2013.

14 Ando N, Kato H, Igaki H, Shinoda M, Ozawa S, Shimizu H, Nakamura T, Yabusaki H, Aoyama N, Kurita A, Ikeda K, Kanda T, Tsujinaka T, Nakamura $\mathrm{K}$ and Fukuda $\mathrm{H}$ : A randomized trial comparing postoperative adjuvant chemotherapy with cisplatin and 5-fluorouracil versus preoperative chemotherapy for localized advanced squamous cell carcinoma of the thoracic esophagus (JCOG9907). Ann Surg Oncol 19: 68-74, 2012.

15 Saeki H, Morita M, Nakashima Y, Sonoda H, Hashimoto K, Egashira A, Oki E, Ohga T, Kakeji Y and Maehara Y: Neoadjuvant chemoradiotherapy for clinical stage II-III esophageal squamous cell carcinoma. Anticancer Res 31: 3073-3077, 2011.

16 Matsuda S, Takeuchi H, Kawakubo H, Ando N and Kitagawa Y: Current Advancement in multidisciplinary treatment for resectable cstage ii/iii esophageal squamous cell carcinoma in Japan. Ann Thorac Cardiovasc Surg 22: 275-283, 2016.

17 Nakamura K: Kato K, Igaki H, Ito Y, Mizusawa J, Ando N, Udagawa H, Tsubosa Y, Daiko H, Hironaka S, Fukuda $\mathrm{H}$ and Kitagawa Y: Three-arm phase III trial comparing cisplatin plus 5-FU (CF) versus docetaxel, cisplatin plus 5-FU (DCF) versus radiotherapy with $\mathrm{CF}$ (CF-RT) as preoperative therapy for locally advanced esophageal cancer (JCOG1109, NExT study). Jpn J Clin Oncol 43: 752-755, 2013.

Received October 13, 2018

Revised October 23, 2018

Accepted November 1, 2018 